\title{
Hemodialysis and hepatitis $B$ vaccination: a challenge to physicians
}

\author{
This article was published in the following Dove Press journal: \\ International Journal of General Medicine \\ 3 February 2014 \\ Number of times this article has been viewed
}

\author{
Munir Akar Ayub' \\ Marcelo Rodrigues Bacci ${ }^{2}$ \\ Fernando Luiz Affonso \\ Fonseca $^{3}$ \\ Ethel Zimberg Chehter ${ }^{4}$ \\ 'Department of Infectology, \\ 2Department of General Practice, \\ ${ }^{3}$ Department of Morphology, \\ ${ }^{4}$ Department of Gastroenterology, \\ Faculdade de Medicina do ABC, Santo \\ André-São Paulo, Brazil
}

\begin{abstract}
Hepatitis B is responsible for the development of half of hepatocellular carcinoma cases and is a major cause of hepatic insufficiency. The vaccine against hepatitis B virus does not exhibit the same high efficacy in patients on hemodialysis as it does in immunocompetent individuals. The medical literature recommends vaccination with four doses ( $40 \mathrm{mg}$ each) of the hepatitis B virus vaccine before beginning hemodialysis; however, approximately one-third of hemodialysis patients do not respond to this vaccination schedule. A new serologic test should be performed each year for individuals who respond adequately, whereas a booster dose should be offered to those with antibody titers below $10 \mathrm{mIU} / \mathrm{mL}$. In this study, we followed 83 hemodialysis patients and collected quantitative serologic measurements every 2 months over a 1 -year period. We made the measurements 1 month after the vaccination period. We found that $41 \%$ of the patients had antibody titers below $10 \mathrm{mIU} / \mathrm{mL}$ (nonresponders), $21.7 \%$ had antibody titers between $10 \mathrm{mIU} / \mathrm{mL}$ and $100 \mathrm{mIU} / \mathrm{mL}$ (poor responders), and $37.3 \%$ had antibody titers higher than $100 \mathrm{mIU} / \mathrm{mL}$ (good responders). Patients with diabetes and/or hypertension exhibited worse response to vaccination. All subjects displayed decreasing antibody titers during the observation period. The group of poorly responsive patients had antibody titers below $10 \mathrm{mIU} / \mathrm{mL}$ at the 6-month follow-up period.
\end{abstract}

Keywords: hepatitis B vaccination, chronic kidney disease, hemodialysis

\section{Introduction}

Hepatitis B (HB) is the most prevalent source of viremia and one of the major causes of liver disease and cirrhosis. ${ }^{1}$ Hepatocellular carcinoma is the sixth most common cancer worldwide, and half of all cases are consequent to chronic HB virus (HBV) infections. After tobacco, HBV is the most significant carcinogenic factor. ${ }^{2}$ The World Health Organization estimates that $40 \%$ of the global population has had contact with or is a chronic carrier of $\mathrm{HBV}^{3}$ Currently, it is estimated that 360 million people are chronic carriers, resulting in approximately 700,000 deaths per year worldwide that are either directly or indirectly related to $\mathrm{HBV}^{3,4}$

HBV transmission happens through percutaneous or mucosal exposition to infectious blood or body fluids. However, the primary forms of HBV transmission are limited nowadays and remain through sexual contact with multiple partners, among men having sex with men, drug injection users, and perinatal transmission. ${ }^{5}$

The prevalence of infection is varied worldwide. The Centers for Disease Control and Prevention (CDC) keeps an update map of HBV infection prevalence. Higher prevalence $(\geq 8 \%)$ is seen in most parts of Africa, Middle and South Asia, and in the Andes region of Colombia and Peru. Intermediate prevalence $(2 \%-7.9 \%)$ is seen in 
most parts of Brazil, Russia, and Eastern Europe. The lowest percentage of prevalence $(<2 \%)$ is in the US, Canada, Australia, and in the southern region of South America. ${ }^{6}$

Moreover, the incidence of HBV among some population groups is alarming, reaching $15 \%$ in human immunodeficiency virus (HIV) patients and nearly 30\% in drug users. $^{7,8}$

Patients on chronic hemodialysis are considered high risk because many of the diagnostic and therapeutic procedures routinely used in this group increase the probability of $\mathrm{HBV}$ infection. ${ }^{9}$

There are two distinct forms of HBV infection among individuals undergoing chronic hemodialysis: the first form is characterized by the triad of infected patients, health care workers, and uninfected patients. The second form is by transfusions of contaminated blood or blood derivatives and the risk of blood exposure in the frequent percutaneous procedures that these patients are exposed to. ${ }^{10} \mathrm{HBV}$ is stable and resilient; it can remain viable for up to 7 days at room temperature on the surfaces of utensils, medical supplies, and other objects. ${ }^{11}$ Thus, the primary means of protection for individuals on dialysis is a targeted vaccination strategy against HBV. Improvements in quality of medical care and hygienic measures followed in hemodialysis units also contribute positively to protection.

The number of patients treated with dialysis worldwide is growing rapidly. According to the 2008 census in Brazil, there were approximately 90,000 people on hemodialysis, an increase of more than 50\% compared with $2004 .^{12}$ The prevalence of $\mathrm{HB}$ in this population has decreased significantly (to $0.9 \%$ in the US and to $2 \%$ in Brazil) through preventive measures, such as the routine vaccination of patients and health care workers, the regular use of erythropoietin as a substitute for blood transfusions, early serological diagnosis, the isolation of infected patients, and cleaning and disinfecting procedures. ${ }^{13}$

The CDC and the Brazilian Ministry of Health recommend routine $\mathrm{HBV}$ vaccination prior to dialysis with four doses of $40 \mu \mathrm{g}$ each administered intramuscularly in the deltoid within $0,30,60$, and 180 days of the procedure. ${ }^{15}$ Several worldwide studies have shown that one-third of these patients do not respond adequately to immunization. ${ }^{16}$ Individuals who carry antibodies against the HBV surface antigen (anti-HBs) above $10 \mathrm{mIU} / \mathrm{mL}$ are considered to be protected. For chronic kidney disease patients who do not respond to the primary vaccination, a new schedule with four doses of $40 \mu \mathrm{g}$ is recommended. Therefore, in hemodialysis patients who respond to vaccination, serological control testing should be performed annually, and a new booster dose is recommended for those who present with antibody titers that are considered to be non-protective $(<10 \mathrm{mIU} / \mathrm{mL}) .{ }^{15}$

Few studies have closely followed the temporal evolution of the concentrations of anti-HBs in hemodialysis patients. Pin et al found that only $67.8 \%$ of subjects remained immune after a 1 -year follow-up and $16 \%$ of subjects were already susceptible prior to their 6-month follow-up. ${ }^{16}$

The objective of the study was to identify the pattern of $\mathrm{HB}$ vaccination response of hemodialysis patients and when they become serologically negative for anti-HBs. The secondary aim was to analyze the interference of clinical variables with the immunological response to $\mathrm{HB}$ vaccination.

\section{Methods}

We followed 102 patients who were being treated at two hemodialysis clinics in the southeastern region of Brazil in the period of March 2009 to April 2010. All the patients signed informed consent forms.

The inclusion criteria encompassed individuals with chronic renal failure who were just starting on hemodialysis 30 days after the complete vaccination schedule against HBV. Such individuals did not have concomitant diseases known to decrease the immunological response (acquired immunodeficiency syndrome or malignant neoplasms) and with no usage of immunosuppressive drugs (high doses of corticosteroids or chemotherapy). We excluded patients chronically infected (surface antigen of HBV [HBsAg] or anti-HBc [hepatitis B core antibody] positive) who were taking antiviral drugs, as well as those co-infected with HIV or hepatitis $\mathrm{C}$, and hemodialysis patients with previous history of poor response to $\mathrm{HBV}$ immunizations.

The vaccines used were made with recombinant DNA technology by GlaxoSmithKline (Engerix-B ${ }^{\circledR}$; London, UK) or by the Butantan Institute of São Paulo, and they were administered in double doses (40 $\mu$ g each) according to the National Immunization Program recommendations.

The patients were then stratified according to age, the primary cause of renal disease, the presence or absence of tobacco use, and the presence or absence of occasional comorbidities (diabetes mellitus, hypertension, or autoimmune diseases).

Blood samples were collected every 2 months to perform quantitative tests, measuring the anti-HBsAg using the same reference laboratory. The method employed to analyze the antibody titers was a semi-quantitative microparticle enzyme immunoassay using an Abbott AxSYM microparticle enzyme immunoassay analyzer (Abbott Laboratories, Abbott Park, IL, USA). Only patients with at least three consecutive bimonthly blood collections were included in the sample. 


\section{Statistical analysis}

The continuous variable used for the analysis of the patient's profile included the age in years of the patients. The categorical variables applied encompassed sex, hypertension, diabetes, and smoking defined as a regular cigarette consumption.

For the quantitative variables, the analysis was obtained by mean and standard deviation calculation. For the qualitative variables, the absolute and relative frequencies were used.

The evaluation of homogeneity between proportions of the qualitative variables was performed using the chi-square test or Fisher's exact test when there were expected frequencies less than five.

For a three-group comparison, the two-way analysis of variance (ANOVA) was used by the Bonferroni test, and when the supposition of data normality was rejected, the nonparametric Kruskal-Wallis test was applied with Dunn's pairwise comparison test.

The significance level applied for the tests was $5 \%$. The statistical package used in this study was SPSS, version 17.0, for Windows (IBM Corporation, Armonk, NY, USA).

\section{Results}

Our final sample consisted of 83 patients: 44 females (53\%) and 39 males (47\%). Their ages ranged from 15 to 86 years with a mean age of 55.1 years. During the study, there were ten deaths from complications secondary to disease, five transfers to other facilities, three referrals for kidney transplants, and one voluntary withdrawal for personal reasons after the initial sample collections.

We observed three response patterns to the immunizations: the nonresponders $(41 \%)$ never reached the minimum protective titer of $10 \mathrm{mIU} / \mathrm{mL}$, the poor responders $(21.7 \%)$ had titers between 10 and $100 \mathrm{mIU} / \mathrm{mL}$, and the good responders $(37.3 \%)$ had antibody titers above $100 \mathrm{mIU} / \mathrm{mL}$.

Some had antibody titers that were extremely close to the cut-off level (12 mIU/mL, for example) and thus were quickly deemed susceptible in subsequent measurements. Other patients presented with increased antibody titers during the study, which may have occurred due to a continuing immune response to vaccination. There was no evidence of a first contact to HBV.

We found that despite a reduction in anti-HBs over time, the good responders did not become unprotected during the observation period, especially those participants who had titers above $1,000 \mathrm{mIU} / \mathrm{mL}$ after the initial immunization.

There were no statistically significant differences in the response to the vaccination in terms of age $(P=0.17)$, tobacco use $(P=0.36)$, or the presence of autoimmune diseases $(P=0.96)$. Non-diabetic and non-hypertensive patients responded better to the vaccination $(P=0.02$ and $P=0.01$, respectively). The stratified analysis also demonstrated that the patients with concomitant hypertension and diabetes mellitus responded poorly to immunization $(P=0.001)$ (Table 1). The good responders maintained high antibody titers over time, which were sufficient to maintain protection throughout the year. This fact was most evident in those patients who had titers above $1,000 \mathrm{IU} / \mathrm{mL}$ from the first measurement that followed vaccination. We also determined that $55.5 \%$ of the poor responders became susceptible before completing 1 year of follow-up. At the fourth collection 1 month after the last vaccine dose, $44.4 \%$ of the participants had undetectable titers and were therefore prone to HBV infection (Figure 1).

Table I Biodemographic data relating to the $\mathrm{HB}$ vaccination response level in hemodialysis patients

\begin{tabular}{|c|c|c|c|c|}
\hline \multirow{2}{*}{$\begin{array}{l}\text { Variable } \\
\text { (number) }\end{array}$} & \multicolumn{3}{|l|}{ Titer level $\mathrm{mlU} / \mathrm{mL}$} & \multirow[t]{2}{*}{$P$-value } \\
\hline & $\begin{array}{l}\text { Nonresponders } \\
<10 \mathrm{mIU} / \mathrm{mL}, \mathrm{n}(\%)\end{array}$ & $\begin{array}{l}\text { Poor responders } \\
10-100 \mathrm{mlU} / \mathrm{mL}, \mathrm{n}(\%)\end{array}$ & $\begin{array}{l}\text { Good responders } \\
>100 \mathrm{mlU} / \mathrm{mL}, \mathrm{n}(\%)\end{array}$ & \\
\hline Male (39) & $20(5 \mid .2)$ & $7(17.9)$ & $12(30.7)$ & $0.27^{*}$ \\
\hline Female (44) & |4 (31.8) & II (25) & $19(43.2)$ & \\
\hline \multicolumn{5}{|l|}{ Age } \\
\hline I5-29 years (7) & $2(28.5)$ & $3(42.8)$ & $2(28.5)$ & $0.171^{\alpha}$ \\
\hline $30-59$ years $(61)$ & $25(40.9)$ & $12(19.6)$ & $24(39.3)$ & \\
\hline$>60$ years $(15)$ & $7(46.6)$ & $3(20)$ & $5(30)$ & \\
\hline Smoking (II) & $6(54.5)$ & $3(27.2)$ & $2(18.1)$ & $0.368^{\perp}$ \\
\hline Diabetes (32) & $19(59.3)$ & $5(15.6)$ & $8(25)$ & $0.026 *$ \\
\hline Hypertension (36) & $21(58.3)$ & $7(19.4)$ & $8(22.2)$ & $0.013^{*}$ \\
\hline Lupus (9) & $4(44.4)$ & $2(22.2)$ & $3(33.3)$ & $0.963^{\Delta}$ \\
\hline
\end{tabular}

Notes: *Chi-square test. ${ }^{\alpha}$ ANOVA. ${ }^{4}$ Fisher's exact test.

Abbreviations: ANOVA, analysis of variance; $H B$, hepatitis B. 




Figure I Trend of antibody titers in low responders. This chart represents the decrease over time of patients with anti-HBS titer confering protection against the HBV. There is a trend of reduction of these titers over a year.

\section{Discussion}

In adults with normal immune systems, an HBV infection progresses with the production of neutralizing antibodies, the consequent elimination of the virus, and the development of immunity against future infection in $94 \%$ to $98 \%$ of individuals. In newborns and immunosuppressed individuals, including those on hemodialysis, the majority of these infections result in chronic disease with prevalence of the HBsAg without the production of protective antibodies. ${ }^{15}$ The medical literature contains several studies showing that the response of chronic renal failure patients is inferior to that of the general population. ${ }^{17}$

Concerning the specific response to $\mathrm{HBV}$ vaccination, several additional factors contribute to an inefficient immune protection in chronic renal failure patients, such as advanced age (over 60 years), prolonged hemodialysis, co-infection with hepatitis $\mathrm{C}$ virus and/or HIV, tobacco use, diabetes mellitus, malnutrition, and low adequacy dialysis levels. ${ }^{18-21}$ No differences have been found in the rates of seroconversion between patients on peritoneal dialysis and those on hemodialysis. ${ }^{22}$

Promising agents in order to improve its response like AS02 (Engerix-B ${ }^{\circledR}$ ) and after AS04 (Fendrix ${ }^{\circledR}$ ) adjuvanted HB vaccines which have already proven to be superior to the ordinary regimen. ${ }^{23}$

Several researchers have been studying ways to increase the effectiveness of vaccinations by using higher doses of antigen; administering the vaccines intradermally; dispensing multiple sequential intradermal doses; administering HB vaccinations along with hepatitis A vaccines; simultaneously using immunomodulators, such as levamisole or interleukins; and conjugating a new aluminum adjuvant to $\mathrm{HBsAg}$, which is the most promising of these techniques. ${ }^{24-29}$ Our findings are consistent with other published results, in which an average of $30 \%$ to $40 \%$ of hemodialysis patients remain susceptible to HBV despite being vaccinated according to the present recommendations.

The results of anti-HBs serologic tests are usually expressed qualitatively, with positive results for titers higher than $10 \mathrm{mIU} / \mathrm{mL}$ and negative for titers below this level. ${ }^{30}$

This study demonstrates that patients may exhibit titers close to the edge of protection but they may quickly become unprotected due to a fall in antibody titers over time. Chaves et $\mathrm{al}^{31}$ demonstrated that the majority of poor responders dialysis patients did not show protective titers after 1 year, with only $44 \%$ with positive results. However, there is a slightly positive relation with a good response $(>100 \mathrm{mIU} / \mathrm{mL})$ and the maintenance of protection. About $92 \%$ of the good responders in this series remained protected after 1 year, with a decrease to $68 \%$ in 24 months. ${ }^{31}$

Lin et $\mathrm{al}^{32}$ have shown an HB response vaccination rate of $70.5 \%$ in 156 dialysis patients. Elderly, malnourished, and diabetic patients had a worse response than the other dialysis patients. ${ }^{32}$

Our major concern was the poor responders because many of them become susceptible prior to the serological control tests, performed 1 year after the vaccination series as advised by the CDC and the National Immunization Program. 
We showed that $55.6 \%$ of those patients were negative after 1 year of follow-up.

Our data revealed that $33.3 \%$ were negative for anti-HBs at the 4-month collection, and $11.1 \%$ more had become negative at the 6 -month collection, totaling $44.4 \%$ of susceptible individuals.

In this group, revaccination could be anticipated based on the patients' anti-HBs titer levels 6 months after the completion of the vaccination scheme.

In conclusion, we demonstrated that chronic kidney disease patients in hemodialysis have different patterns of response to the $\mathrm{HB}$ vaccination scheme. There is a trend toward a reduction in antibody titers over time. Even with the $40 \mu \mathrm{g}$ dose, $41 \%$ of hemodialysis patients did not respond to $\mathrm{HBV}$ vaccination.

\section{Disclosure}

The authors report no conflicts of interest in this work.

\section{References}

1. Centers for Disease Control and Prevention (CDC). Characteristics of persons with chronic hepatitis B - San Francisco California, 2006. MMWR Morb Mortal Wkly Rep. 2007;56(18):446-448.

2. Parkin DM, Bray F, Ferlay J, Pisani P. Estimating the world cancer burden: Globocan 2000. Int J Cancer. 2001;94(2):153-156.

3. Goldstein ST, Zhou F, Hadler SC, Bell BP, Mast EE, Margolis HS. A mathematical model to estimate global hepatitis B diseases burden and vaccination impact. Int J Epidemiol. 2005;34(6): 1329-1339.

4. Dienstag JL. Hepatitis B virus infection. N Engl J Med. 2008;359(14): 1486-1500.

5. Edey M, Barraclough K, Johnson DW. Review article: Hepatitis B and dialysis. Nephrology (Carlton). 2010;15(2):137-145.

6. Mast EE, Weinbaum CM, Fiore AE, et al; Advisory Committee on Immunization Practices (ACIP) Centers for Disease Control and Prevention (CDC). A comprehensive immunization strategy to eliminate transmission of hepatitis B virus infection in the United States: recommendations of the Advisory Committee on Immunization Practices (ACIP) Part II: immunization of adults. MMWR Recomm Rep. 2006;55(RR-16):1-33; quiz CE1.

7. Lacombe K, Bottero J, Lemoine M, et al. HIV/hepatitis B virus co-infection: current challenges and new strategies. $J$ Antimicrob Chemother. 2010;65(1):10-17.

8. Marchesini AM, Prá-Baldi ZP, Mesquita F, Bueno R, Buchalla CM. [Hepatitis $\mathrm{B}$ and $\mathrm{C}$ among injecting drug users living with HIV in São Paulo, Brazil]. Rev Saude Publica. 2007;41 Suppl 2:57-63. Portuguese.

9. Alter MJ, Arduino MJ, Lyerla HC, Miller ER, Tokars JI. Recommendations for preventing transmission of infections among chronic hemodialysis patients. MMWR Recomm Rep. 2001;50(RR-5): 1-43; quiz CE1.

10. Fabrizi F, Messa P, Martin P. Hepatitis B virus infection and the dialysis patient. Semin Dial. 2008;21(5):440-446.

11. Bond WW, Favero MS, Petersen NJ, Gravelle CR, Ebert JW, Maynard JE. Survival of hepatitis B virus after drying and storage for one week. Lancet. 1981;1(8219):550-551.

12. Sesso R, Lopes AA, Thomé FS, Bevilacqua JL, Romão Junior JE, Lugon J. Brazilian Dialysis Census Report 2008. J Bras Nefrol. 2008;30(4):233-238.
13. Wasley A, Kruszon-Moran D, Kuhnert W, et al. The prevalence of hepatitis B virus infection in the United States in the era of vaccination. J Infect Dis. 2010;202(2):192-201.

14. Chow KM, Law MC, Leung CB, Szeto CC, Li PK. Antibody response to hepatitis B vaccine in end-stage renal patients. Nephron Clin Pract. 2006;103(3):c89-c93.

15. Centers for Disease Control and Prevention (CDC). Outbreaks of hepatitis B virus infection among hemodialysis patients - California, Nebraska and Texas. 1994. MMWR Morb Mortal Wkly Rep. 1996;45(14):285-289.

16. Pin M, Compte MT, Angelet P, Gállego C, Gutiérrez C, Martinez Vea A. [Long-term evaluation of immune response to hepatitis $\mathrm{B}$ vaccine in 136 patients undergoing hemodialysis]. Nefrologia. 2009;29(5): 415-420. Spanish.

17. Pesanti MD. Immunologic defects and vaccination in patients with chronic renal failure. Infect Dis Clin North Am. 2001;15(3): 813-832.

18. Jadoul M, Goubau P. Is anti-hepatitis B virus (HBV) immunization successful in elderly hemodialysis patients? Clin Nephrol. 2002;58(4): 301-304.

19. Yu AS, Cheung RC, Keeffe EB. Hepatitis B vaccines. Clin Liver Dis. 2004;8(2):283-300.

20. Ibrahim S, el-Din S, Bazzal I. Antibody level after hepatitis B vaccination in hemodialysis patients: impact of dialysis adequacy, chronic inflammation, local endemicity and nutritional status. $J$ Natl Med Assoc. 2006;98(12):1953-1957.

21. Navarro JF, Terruel JL, Mateos M, Marcen R, Ortuno J. Antibody level after hepatitis B vaccination in hemodiálisis patients: influence of hepatitis C virus infection. Am J Nephrol. 1996;16(2):95-97.

22. Hoofnagle JH, Di Bisceglie AM. Serologic diagnosis of acute and chronic viral hepatitis. Semin Liver Dis. 1991;11(2):73-83.

23. Surquin M, Tielemans CL, Kulcsár I, et al. Rapid, enhanced, and persistent protection of patients with renal insufficiency by AS02(V)adjuvanted hepatitis B vaccine. Kidney Int. 2010;77(3):247-255.

24. Wang C, Sun J, Zhu B, et al. Hepatitis B virus infection and related factors in hemodialysis patients in China - systematic review and meta-analysis. Ren Fail. 2010;32(10):1255-1264.

25. Charest AF, McDougall J, Golstein MB. A randomized comparison of intradermal and intramuscular vaccination against hepatitis B virus in incident chronic hemodialysis patients. Am J Kidney Dis. 2000;36(5): 976-982.

26. Medeiros RH, Figueiredo AE, Poli de Figueiredo CE, d'Avila D, de los Santos CA. Low Response to intradermal hepatites B vaccination in incidente hemodialysis patients. J Bras Nefrol. 2011;33(1):45-49.

27. Medeiros RH, Figueiredo AE, Poli de Figueiredo CE, d'Avila D, de Los Sabtos CA. Intramuscular or intradermal hepatitis B vaccine administration in hemodialysis patients? Am J Kidney Dis. 2009;54(5):981-982; author reply 982.

28. Tung J, Carlisle E, Smieja M, KimPT, Lee CH. A randomized clinical trial of immunization with combined hepatitis A and B versus hepatitis B alone for hepatitis B seroprotection in hemodialysis patients. Am J Kidney Dis. 2010;56(4):713-719.

29. Alavian SM, Tabatabaei SV. Effects of oral levamisole as an adjuvant to hepatitis B vaccine in adults with end-stage renal disease: a metaanalysis of controlled clinical trials. Clin Ther. 2010;32(1):1-10.

30. Tielemans CL, Vlasak J, Kosa D, et al. Immunogenicity and safety of an investigational AS02(v)-adjuvanted hepatitis B vaccine in patients with renal insufficiency who failed to respond or to maintain antibody levels after prior vaccination: results of two open, randomized, comparative trials. Vaccine. 2011;29(6):1159-1166.

31. Chaves SS, Daniels D, Cooper BW, et al. Immunogenicity of hepatitis B vaccine among hemodialysis patients: effect of revaccination of non-responders and duration of protection. Vaccine. 2011;29(52): 9618-9623.

32. Lin SY, Liu JH, Wang SM, et al. Association of response to hepatitis B vaccination and survival in dialysis patients. BMC Nephrol. 2012;13:97. 


\section{Publish your work in this journal}

The International Journal of General Medicine is an international, peer-reviewed open-access journal that focuses on general and internal medicine, pathogenesis, epidemiology, diagnosis, monitoring and treatment protocols. The journal is characterized by the rapid reporting of reviews, original research and clinical studies across all disease areas.

A key focus is the elucidation of disease processes and management protocols resulting in improved outcomes for the patient.The manuscript management system is completely online and includes a very quick and fair peer-review system. Visit http://www.dovepress.com/ testimonials.php to read real quotes from published authors.

Submit your manuscript here: http://www.dovepress.com/international-journal-of-general-medicine-journal 